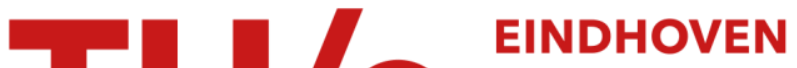 \\ UNIVERSITY OF \\ TECHNOLOGY
}

\section{Aspects of dissociative chemisorption and promotion in catalysis}

Citation for published version (APA):

Niemantsverdriet, J. W. (1995). Aspects of dissociative chemisorption and promotion in catalysis. Applied Physics A: Materials Science \& Processing, 61(5), 503-509. https://doi.org/10.1007/s003390050232

DOI:

10.1007/s003390050232

Document status and date:

Published: 01/01/1995

\section{Document Version:}

Publisher's PDF, also known as Version of Record (includes final page, issue and volume numbers)

\section{Please check the document version of this publication:}

- A submitted manuscript is the version of the article upon submission and before peer-review. There can be important differences between the submitted version and the official published version of record. People interested in the research are advised to contact the author for the final version of the publication, or visit the $\mathrm{DOI}$ to the publisher's website.

- The final author version and the galley proof are versions of the publication after peer review.

- The final published version features the final layout of the paper including the volume, issue and page numbers.

Link to publication

\section{General rights}

Copyright and moral rights for the publications made accessible in the public portal are retained by the authors and/or other copyright owners and it is a condition of accessing publications that users recognise and abide by the legal requirements associated with these rights.

- Users may download and print one copy of any publication from the public portal for the purpose of private study or research.

- You may not further distribute the material or use it for any profit-making activity or commercial gain

- You may freely distribute the URL identifying the publication in the public portal.

If the publication is distributed under the terms of Article 25fa of the Dutch Copyright Act, indicated by the "Taverne" license above, please follow below link for the End User Agreement:

www.tue.nl/taverne

Take down policy

If you believe that this document breaches copyright please contact us at:

openaccess@tue.nl

providing details and we will investigate your claim. 
Appl. Phys. A 61, 503-509 (1995)

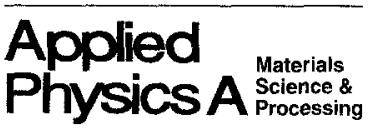

(C) Springer-Verlag 1995

\title{
Aspects of dissociative chemisorption and promotion in catalysis
}

\author{
J.W. Niemantsverdriet \\ Schuit Institute of Catalysis, Eindhoven University of Technology, 5600 MB Eindhoven, The Netherlands \\ (Fax: + 31-40/455054)
}

Received: 27 March 1995/Accepted: 24 July 1995

\begin{abstract}
Catalysis is a cyclic event in which reactants adsorb on the catalyst, react on the surface and desorb into the gas phase, leaving empty adsorption sites behind for the next catalytic cycle. Very often, at least one of the participating reactants has to dissociate. This paper qualitatively reviews the electronic interactions between an adsorbed molecule and the surface that lead to dissociation, and discusses in more detail how alkali metal promoters enhance this interaction by lowering the electrostatic surface potential. As a dissociating molecule generally needs an ensemble of several metal atoms, the kinetics of the dissociation reaction depends sensitively on the surface coverage, as is illustrated for the dissociation of NO on rhodium.
\end{abstract}

PACS: $82.65 ; 68.10$

Catalysis plays a prominent role in chemical industry. It is estimated that $85 \%$ of all chemicals and fuels or more have been in contact with a catalyst at least once. Catalysis also becomes progressively more important in environmental pollution control. In order to fully understand a catalytic reaction mechanism, it is essential to identify the reaction intermediates and to know the elementary reaction steps along with their kinetic parameters. Surface science has been instrumental in this respect and there is no doubt that catalysis anno 1995 would not be what it is without surface science.

The process of catalysis is essentially a cycle in which reactants adsorb and react on the surface of the catalyst, while products desorb into the gas phase. The catalytic activity is associated with sites on the surface which are continuously regenerated. The role of the catalyst is to provide an energetically favourable pathway for the reaction. Figure 1 schematically illustrates the catalytic cycle for the reaction $\mathrm{NO}+\mathrm{CO} \rightarrow 1 / 2 \mathrm{~N}_{2}+\mathrm{CO}_{2}$. This is a very important reaction in automotive exhaust catalysis [1], which has been the subject of many surface science investigations [2-4].
Where lies the essential influence of the catalyst? Predominantly in the dissociation of the $\mathrm{N}-\mathrm{O}$ bond. The reason that reactions such as those between $\mathrm{NO}$ and $\mathrm{CO}$, or between $\mathrm{CO}$ and $\mathrm{O}_{2}$ do not proceed in the gas phase is that very high temperatures would be required in order to break the $\mathrm{N}-\mathrm{O}$ and $\mathrm{O}-\mathrm{O}$ bonds. Once atomic oxygen and nitrogen are available, they will readily recombine to form $\mathrm{CO}_{2}$ and $\mathrm{N}_{2}$. Thus, in general, one can say that the essential action of the catalyst is to dissociate bonds; consecutive reactions follow-temperature and surface concentrations permitting - more or less automatically. In other words, catalysts break bonds and let new bonds form.

This paper reviews some of our recent work on surface dissociation. First, we discuss dissociation of molecules on surfaces on an introductory level in terms of qualitative, highly simplified, molecular orbital language $[5,6]$. Then, we show how promoters such as alkali metals configure the electrostatic potential of a metal surface in a way that dissociation is favored, and finally, we discuss how the kinetics of dissociation depends sensitively on surface coverage, or more essentially, on the availability of free sites.

\section{Qualitative molecular orbital picture of dissociative chemisorption}

In order to analyze the interaction between a molecule and the catalytic surface that leads to molecular or dissociative chemisorption, it is useful to consider the metaladsorbate system as a 'surface molecule'. This complex has molecular orbitals made up from metal orbitals and orbitals of the adsorbing molecule [7].

If we want to understand the conditions under which a chemisorbed diatomic molecule such as $\mathrm{H}_{2}, \mathrm{~N}_{2}$ or $\mathrm{CO}$ dissociates, we need to take two orbitals of the molecule into account, the Highest Occupied and the Lowest Unoccupied Molecular Orbital (the HOMO and the LUMO). For simplicity, we consider a molecule $\mathrm{A}_{2}$ with a doubly occupied bonding level $\sigma$ and an unoccupied antibonding 


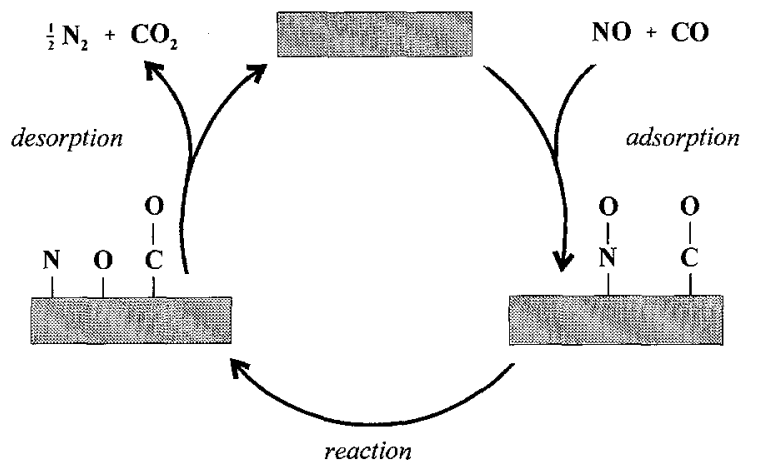

Fig. 1. Catalysis represented as a cycle in which reactants adsorb and react on the surface, and products desorb leaving free surface behind for the next catalytic turnover

level $\sigma^{*}$, as in $\mathrm{H}_{2}$. The overlap between the electron densities of the metal and the adsorbing molecule gives rise to the formation of new orbitals for the chemisorption complex. As the participating electrons from the metal come from broad bands, the chemisorption orbitals are broad as well. These are the necessary steps (Fig. 2):

(i) Construct orbitals from the HOMO, here the bonding orbital $\sigma$ of $\mathrm{A}_{2}$ and levels in the surface with appropriate orientation and symmetry;

(ii) Do the same for the LUMO, the $\sigma^{*}$ of $\mathrm{A}_{2}$ and metal levels of appropriate orientation and symmetry;

(iii) See where the levels are with respect to the Fermi level of the metal and find out to what extent the chemisorption orbitals are filled.

What are the important things to look at? First, the interaction under $(i)$ between the occupied molecular $\sigma$ orbital and an occupied surface orbital gives an in-principle repulsive interaction, because both the bonding and the antibonding chemisorption orbital will be occupied. However, if the antibonding orbital falls above the Fermi level, the repulsion is partially or entirely relieved. Second, interaction (ii) gives a bonding orbital which can either be above or below the Fermi level. Since the participating
LUMO orbital of the adsorbing molecule is antibonding with respect to the interaction between the molecule atoms, occupation of the corresponding orbital fragments leads to dissociation of the molecule. Be it partially occupied, then it contributes less to bonding between $\mathrm{A}_{2}$ and the surface, while at the same time the intramolecular $\mathrm{A}-\mathrm{A}$ bond of the chemisorbed molecule is weakened (as is the case with the $2 \pi^{*}$ orbital of CO on most group-VIII metals).

Because the latter process leads to a population of the antibonding molecular orbital by electrons from the metal, it is often referred to as 'back donation'. The partial filling of levels, which are bonding for the metal-molecule interaction but antibonding for the adsorbed molecule, creates a favourable starting position for dissociation, with an activation barrier that is much lower than that for dissociation in the gas phase. It should be noted, however, that the intramolecular bond weakening in the case of adsorbed $\mathrm{CO}$ is only modest, and that sufficient filling of the $2 \pi^{*}$ derived chemisorption levels occurs only when the molecule is in the transition state for dissociation. The latter can be envisaged as a state in which the molecule bends toward the surface, such that the overlap between metal $d$ states and the $2 \pi^{*}$ levels is large $[7,8]$. The reader is referred to the literature for more thorough descriptions of chemisorption theory [7,9-14].

\section{Alkali promoters and the electrostatic surface potential}

The simple orbital scheme of Fig. 2 can be used to illustrate another important factor, namely the role of the work function. Note that the vacuum level in Fig. 2 represents the zero of energy for the electrons in the metal and the adsorbed molecule. Hence, a smaller work function increases the probability that electrons occupy the chemisorption orbitals. This enhances the interaction between the molecule and the surface through filling of the $\sigma^{*}$-derived levels and weakens the intramolecular bond to a greater extent.

Figure 3 shows the well-known picture of how the potassium coverage affects the macroscopic work function. The interpretation of Fig. 3 is that at low coverages

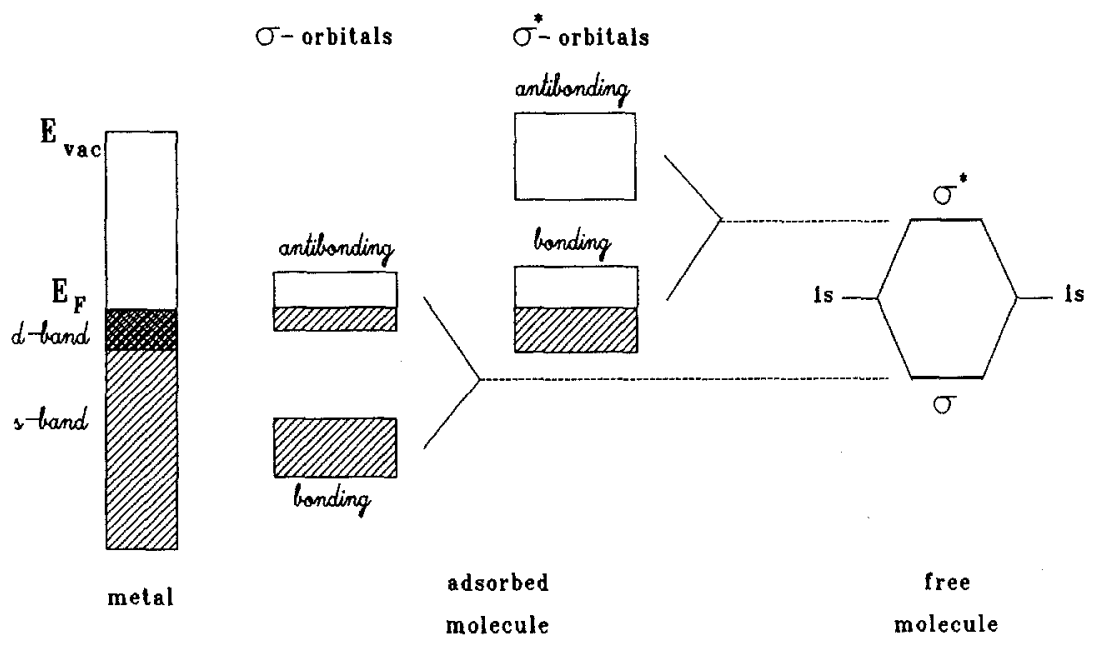

Fig. 2. Orbital scheme for chemisorption of a diatomic molecule on a $d$-metal [6] 


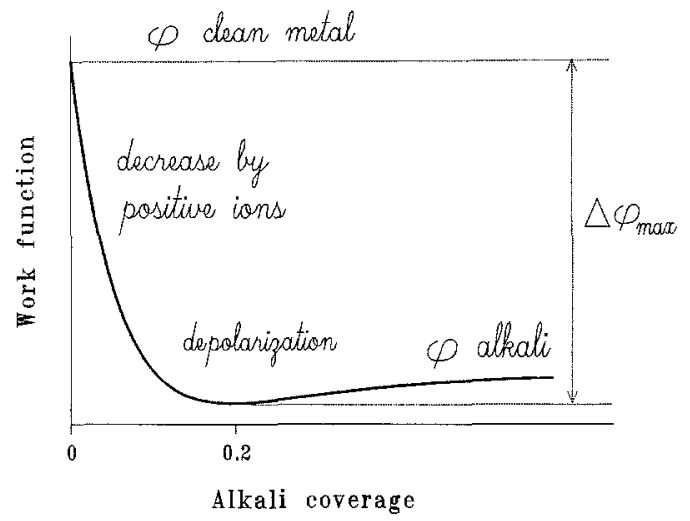

Fig. 3. Work function of alkali-metal-promoted surfaces as a function of alkali metal coverage [6]

the potassium forms a positive ion, which, because it is screened by electrons inside the metal, forms a dipole with the positive end directed outwards. This counteracts the dipole layer of the metal that constitutes the surface contribution to the work function of the substrate. At higher coverages, the effect becomes weaker due to mutual depolarization of the $\mathrm{K}$ atoms. Coverages corresponding to promoter concentrations of practical interest are all in the range where the potassium is atomically dispersed and can almost be conceived as a $\mathrm{K}^{+}$ion [15-17].

Of course, adsorbed molecules do not experience a surface with a homogeneously decreased work function, but feel predominantly the influence of the nearby $\mathrm{K}$ atoms. A calculation of the electrostatic potential around a single potassium atom on a semi-infinite jellium surface by Lang et al. [18] indicates that the promoter effect of the potassium atom is highly local and limited to the adjacent adsorption site only.

What happens if the surface coverage of the alkali metal is higher? Janssens et al. [19] used photoemission of adsorbed noble gases to investigate the electrostatic surface potential on the potassium-promoted (111) surface of rhodium. In order to probe the potential at several distances from the potassium atoms, not only xenon, the commonly used noble gas in this type of study [20], but also krypton and argon were used. Figure 4 plots the shifts in binding energy of the physisorbed noble gases with respect to clean rhodium vs the distance to the potassium atom. As explained in detail by Wandelt [20], this shift in binding energy can be considered as the change in the local work function, which is equivalent to the change in the electrostatic surface potential. Density functional calculations on rhodium-potassium clusters such as $\mathrm{Rh}_{15} \mathrm{~K}_{3}$ confirm the validity of this interpretation [21]. The general picture that emerges from Fig. 4 is that the surface potential changes steeply in the immediate vicinity of the potassium atom, while it becomes more or less constant at distances larger than about $0.5 \mathrm{~nm}$. However, this value is significantly lower than on clean $\mathrm{Rh}(111)$ and depends on the potassium coverage: The long-range effect of adsorbed potassium corresponds to a lowering of the local work function of about $0.4 \mathrm{eV}$ for a potassium coverage of $2.7 \%$ at. $\%$, and of about $1.0 \mathrm{eV}$ for 5 at. $\%$ of potassium on the surface [19].

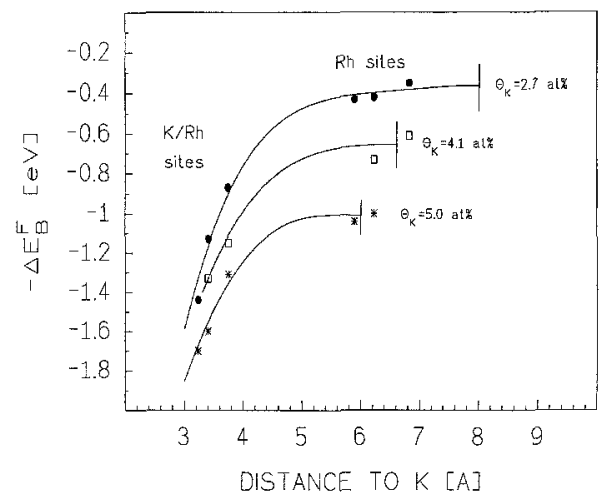

Fig. 4. The UPS binding energy shift of the probe gases $\mathrm{Xe}, \mathrm{Kr}$ and Ar on K-promoted metals measures the electrostatic potential on the surface [9]

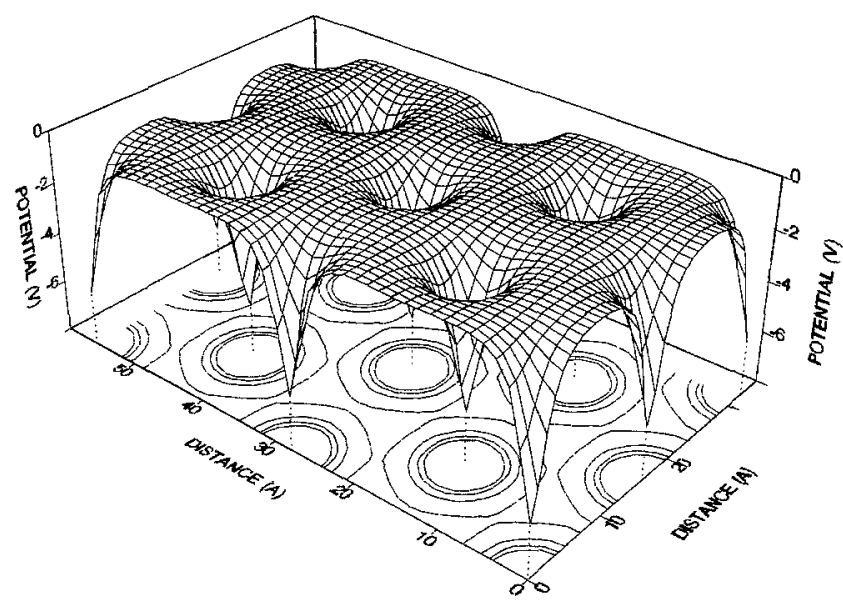

Fig. 5. Three-dimensional map of the electrostatic potential at $0.25 \mathrm{~nm}$ above the symmetry plane in a hexagonally ordered network of dipoles on the rhodium (111) surface. The dipoles are situated at the minima [19]

The long-range effect of the promoter is a result of the cumulative electrostatic effect of all potassium atoms on the surface. Figure 5 gives the result of a theoretical calculation of the electrostatic potential caused by an ordered network of dipoles, corresponding to a potassium coverage of 2.7 at. $\%$ and an average distance between the promoter atoms of $1.6 \mathrm{~nm}$. This calculation confirms that both the short-and the long-range promoter effect of potassium have a purely electrostatic origin. Effects through the substrate, associated with charge donated by potassium to the substrate metal, do not have to be invoked at all.

The catalytic significance of Fig. 5 is that it represents the differences in the effective work functions that a molecule experiences upon adsorption at different positions on the surface. As explained above, a low work function of the substrate enhances the capability of the substrate to donate electrons into empty chemisorption orbitals of the adsorbate. If such an orbital is antibonding with respect to an intramolecular bond of the adsorbed molecule, the latter is weakened due to a higher electron occupation. 
The effect of a lower work function is that all orbitals of an adsorbed molecule shift downward with respect to the Fermi level of the substrate. This shift of the occupied levels to higher binding energy has been observed in UPS spectra of adsorbed CO [22], while the shift of the unoccupied part of the $2 \pi^{*}$-derived chemisorption orbital has been observed in inverse photoemission [23]. The overall effect is that the bond between the metal and the $\mathrm{CO}$ becomes stronger while at the same time the intramolecular $\mathrm{CO}$ bond is weakened. Weakening of the $\mathrm{CO}$ bond by potassium has been observed in the vibrational spectra of $\mathrm{CO}$ on several metals [24-27]. The fact that potassium enhances the adsorption bond of $\mathrm{CO}$ with the substrate is revealed by Thermal Desorption Spectroscopy (TDS) in a shift of the CO peak to higher temperatures in TDS [28].

In conclusion, alkali-metal adsorption on metal surfaces results in a dominant lowering of the surface potential on sites adjacent to a potassium atom, and a smaller, but still significant lowering of the potential on sites further away. The long-range effect is caused by a cumulative effect of all potassium atoms on the surface.

\section{Kinetics of dissociative adsorption}

Whether an adsorbed molecule dissociates or not is determined by the thermodynamics of the adsorption states before and after reaction, and the energy barrier between them. While molecules are found to adsorb on a variety of sites (on top, bridged, three-fold), atoms almost always adsorb in sites of three-fold or four-fold coordination. As a consequence, the dissociation of a molecule is only possible if sufficient free sites are available in the immediate vicinity of the adsorbed molecule. We expect that the total surface coverage has a drastic effect on the dissociation kinetics, as the following derivation suggests [29].

Consider the case where the molecularly adsorbed species $A_{\text {ads }}$ is the majority reaction intermediate in the surface reaction from $\mathrm{AB}$ to adsorbed atoms. In order to understand the kinetics of dissociative adsorption, it is essential to realize that surface sites, indicated with an asterisk, play the role of a reactant in the kinetic equations. The scheme of reactions becomes:

$$
\begin{aligned}
& \mathrm{AB}+* \underset{k_{\mathrm{ads}}}{\stackrel{k_{\mathrm{des}}}{\rightleftarrows}} \mathrm{AB}_{\mathrm{ads}}, \\
& \mathrm{AB}_{\mathrm{ads}}+* \underset{k_{\mathrm{diss}}}{\rightarrow} \mathrm{A}_{\mathrm{ads}}+\mathrm{B}_{\mathrm{ads}} .
\end{aligned}
$$

Note that not only the elementary rate of adsorption, but also the elementary rate of dissociation of the adsorbed molecule depends on the concentration of surface vacancies. When a molecule dissociates, positions for the products have to be available.

Because we are interested in the case that $A B_{\text {ads }}$ is the majority reacting intermediate, implying that the rate constant for dissociation is small, we write the coverage of $\mathrm{AB}_{\mathrm{ads}}$ as:

$\theta_{\mathrm{AB}}=K[\mathrm{AB}] \theta * ; \quad K=k_{\mathrm{ads}} / k_{\mathrm{des}}$.
The site balance becomes:

$\theta_{*}+\theta_{\mathrm{AB}}+\theta_{\mathrm{A}}+\theta_{\mathrm{B}}=1$

and we write the 'coverage of free sites' as

$\theta *=\frac{1-\theta_{\mathrm{A}}-\theta_{\mathrm{B}}}{1+K[\mathrm{AB}]}$.

At the beginning of the reaction the coverages of $\mathrm{A}_{\mathrm{ads}}$ and $\mathrm{B}_{\mathrm{ads}}$ are negligible, and the initial rate of dissociation becomes essentially:

$r_{\mathrm{diss}} \approx k_{\mathrm{diss}} \theta_{\mathrm{AB}}\left(1-\theta_{\mathrm{AB}}\right) \approx \frac{k_{\mathrm{diss}} K[\mathrm{AB}]}{(1+K[\mathrm{AB}])^{2}}$.

The overall activation energy for the dissociation becomes by definition:

$E_{\mathrm{act}}^{\mathrm{eff}}=R T^{2} \frac{\partial}{\partial T} \ln r_{\mathrm{diss}}=E_{\mathrm{act}}^{\mathrm{diss}}+\left(1-2 \theta_{\mathrm{AB}}\right) \Delta H_{\mathrm{ads}}$.

The heat of adsorption (of which the coverage dependence is ignored!) is a negative quantity. Thus, under conditions where $\theta_{\mathrm{AB}}$ is close to unity (i.e., high pressure, low temperature), the overall activation energy is an amount $\left|\Delta H_{\text {ads }}\right|$ higher than the activation energy of the elementary dissociation step. The reason is that there are no sites available for dissociation, hence, it costs an amount of energy equal to $\left|\Delta H_{\text {ads }}\right|$ to free a neighboring site. Note that the expressions of course need to be modified for dissociations requiring more than one free site, as the factor of two derives from the power of the denominator. Temperatureprogrammed measurements on the dissociation kinetics of NO on rhodium illustrate the behavior described above, as discussed in the following section [30].

\section{NO dissociation on $\operatorname{Rh}(111)$}

As said in the introduction, breaking of the $\mathrm{N}-\mathrm{O}$ bond by the surface of rhodium is a highly essential step in the catalytic removal of NO from car exhaust gases. Although rhodium is sufficiently reactive to achieve this (even without promoters), dissociation can nevertheless be severely impeded if the surface coverage is too high. In order to show this, we adsorb NO on the Rh(111) surface at low temperature (about $100 \mathrm{~K}$ ), and use TDS to investigate whether NO stays intact and desorbs as NO, or dissociates and desorbs as $\mathrm{N}_{2}$.

If NO is adsorbed in small amounts (coverages below 0.25 monolayer) all molecules dissociate readily upon heating. This is seen in the thermal desorption spectra of Fig. 6 which shows that $N_{2}$ is the only N-containing desorbing species (traces of the unavoidable contaminant CO desorb around $510 \mathrm{~K}$ ) at low coverage. Desorption of $\mathrm{O}_{2}$ occurs at temperatures above $1200 \mathrm{~K}$ and is not shown. Thus, all NO dissociates at initial coverages below $25 \%$ of a monolayer.

The situation becomes significantly more complex if the surface is covered to a higher extent. For coverages above $25 \%$, the first product to come off the surface upon heating is NO, immediately followed by $\mathrm{N}_{2}$, which desorbs in at least two channels, labeled $\beta_{1}$ and $\beta_{2}$ in Fig. 6. 

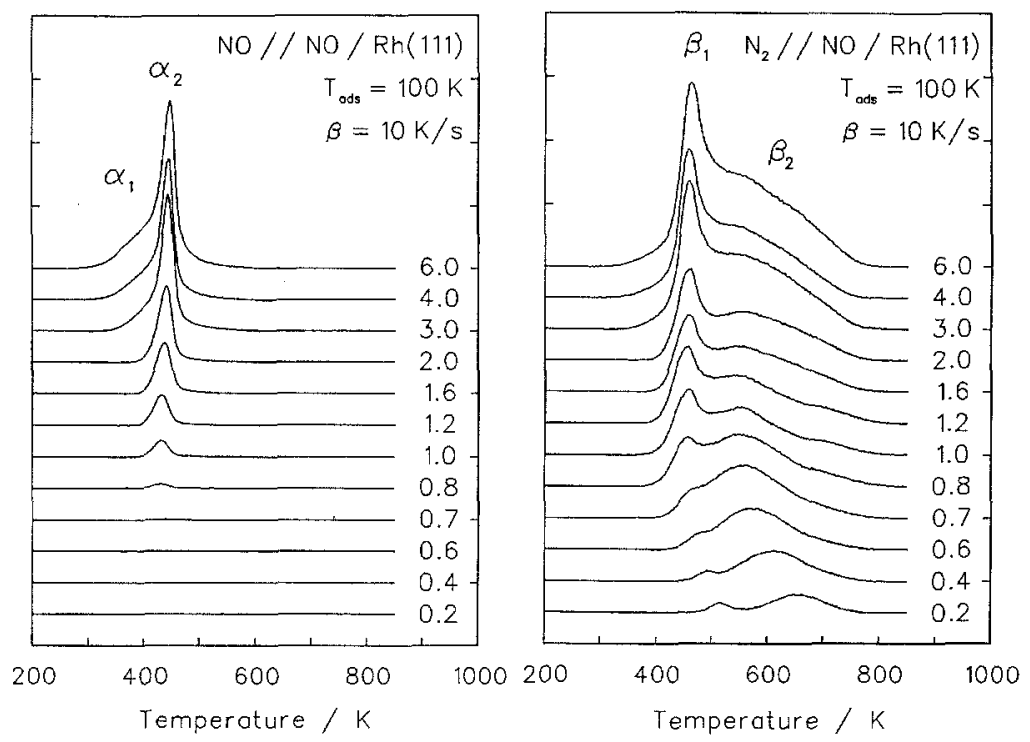

Fig. 6. TPD of $\mathrm{NO}($ left $)$ and $\mathrm{N}_{2}$ (right) after exposing $\mathrm{Rh}(111)$ to various doses of NO given in Langmuir at $100 \mathrm{~K}[30]$
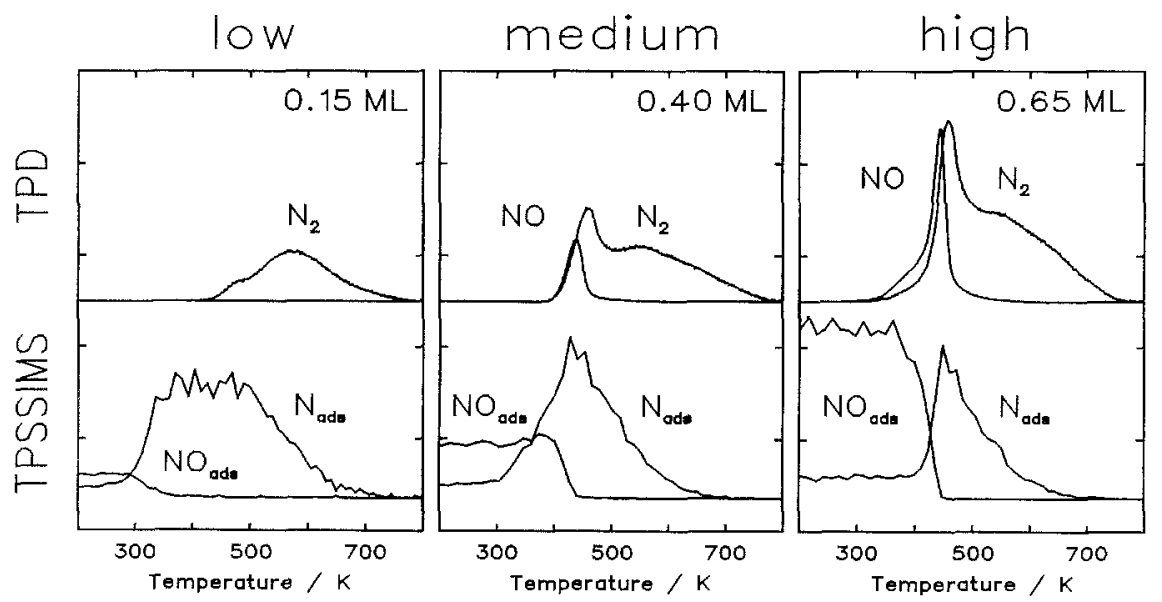

Fig. 7. Temperature-programmed SSIMS and desorption show that NO dissociates completely at low coverages (left) while dissociation at high coverages is retarded to temperatures where NO desorbs [30]
At near saturation coverages, also the $\mathrm{NO}$ desorbs in two states, labeled $\alpha_{1}$ and $\alpha_{2}$. As explained in [30], the $\alpha_{2}$ state is believed to correspond to $\mathrm{NO}$ in a three-fold site. Once these are filled up, NO is assumed to adsorb in two-fold sites, denoted by the $\alpha_{1}$ label. The most important point to note with respect to NO dissociation is that at higher coverages a significant fraction of the adsorbed NO does not dissociate, but desorbs into the gas phase. A detailed interpretation of the reaction mechanism underlying the TPD spectra definitely requires information about what goes on on the surface. For this purpose, Static Secondary-Ion Mass Spectrometry (SSIMS) has proven worthwhile $[31,32]$.

Characteristic cluster ions in SSIMS can be monitored as a function of time by multiplexing the mass spectrometer, enabling in situ studies of surface reactions $[33,34]$. The secondary ions of interest are $\mathrm{RhNO}^{+}$, $\mathrm{Rh}_{2} \mathrm{NO}^{+}$, indicative for molecularly adsorbed $\mathrm{NO}$, and $\mathrm{Rh}_{2} \mathrm{~N}^{+}$, which represents the dissociation product $\mathrm{N}_{\text {ads }}$. As shown extensively by e.g., Brown and Vickerman [35] for $\mathrm{CO}$ on $\mathrm{Ni}, \mathrm{Ru}$ and $\mathrm{Pd}$, intensity ratios such as $\Sigma_{n=1,2}$ $\mathrm{M}_{n} \mathrm{CO}^{+} / \mathrm{M}_{n}^{+}$and $\mathrm{M}_{2} \mathrm{~N}^{+} / \mathrm{M}_{n}^{+}(\mathrm{M}=$ metal$)$, often represent the coverages of adsorbed $\mathrm{CO}$ and $\mathrm{C}$ respectively. We will use the same approach to monitor the surface reactions of $\mathrm{NO}$ and its dissociation products.

Figure 7a shows that NO, preadsorbed at low temperature and at a low coverage of about $15 \%$, dissociates completely at temperatures between 250 and $350 \mathrm{~K}$. This is seen in the SSIMS experiment from the disappearance of the $\mathrm{RhNO}^{+}$signal, reflecting molecular $\mathrm{NO}$, and the growth of the $\mathrm{Rh}_{2} \mathrm{~N}^{+}$signal, characteristic of adsorbed nitrogen atoms. Desorption of molecular $\mathrm{N}_{2}$ starts around $440 \mathrm{~K}$. The results indicate that all NO dissociates at low coverages. If, however, the surface is saturated with $\mathrm{NO}$, dissociation does not set in until a significant fraction of the molecular NO has desorbed, as the SSIMS and Temperature-Programmed Desorption (TPD) measurements of Fig. 7c show. This retards the dissociation of $\mathrm{NO}$ to temperatures around $400 \mathrm{~K}$, where recombination of $\mathrm{N}$ atoms and desorption of $\mathrm{N}_{2}$ follow almost instantaneously. The results exemplify the more general kinetic scheme for the dissociation of $\mathrm{AB}_{\mathrm{ads}}$ given above. If the initial coverage of $\mathrm{NO}$ is high, desorption of a part of the NO molecules has to occur in order to create the free sites that are necessary for its dissociation. 
Table 1. Kinetic parameters for the elementary reaction steps involved in the thermal decomposition and desorption of NO on $\mathrm{Rh}(111)$ [30]

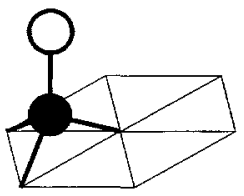

initial state

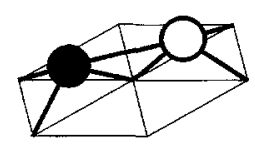

transition state

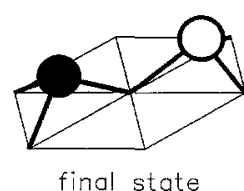

final state
Fig. 8. Schematical representation of NO dissociation on an ensemble of atoms on Rh(111) (adapted from De Koster and Van Santen [8])

The TPD and TPSSIMS support the following sequence of elementary reaction steps for the decomposition of $\mathrm{NO}$ on $\mathrm{Rh}(111)$ :

$$
\begin{aligned}
& \alpha_{2}-\mathrm{NO}_{\mathrm{ads}}+n_{*} \rightarrow \mathrm{N}_{\mathrm{ads}}+\mathrm{O}_{\mathrm{ads}}, T \approx 300 \mathrm{~K}, \\
& \alpha_{1}-\mathrm{NO}_{\mathrm{ads}} \rightarrow \mathrm{NO}_{\mathrm{gas}}+*, T \approx 380 \mathrm{~K}, \\
& \alpha_{2}-\mathrm{NO}_{\mathrm{ads}} \rightarrow \mathrm{NO}_{\mathrm{gas}}+*, T \approx 430 \mathrm{~K}, \\
& \mathrm{~N}_{\mathrm{ads}}+\mathrm{N}_{\mathrm{ads}} \rightarrow \beta_{1}-\mathrm{N}_{2, \mathrm{gas}}+2 *, T \approx 460 \mathrm{~K}, \\
& \mathrm{~N}_{\mathrm{ads}}+\mathrm{N}_{\mathrm{ads}} \rightarrow \beta_{2}-N_{2, \text { gas }}+2 *, T \approx 550-700 \mathrm{~K}, \\
& \mathrm{O}_{\text {ads }}+\mathrm{O}_{\mathrm{ads}} \rightarrow \mathrm{O}_{2, \text { gas }}+2 *, T \approx 1200-1350 \mathrm{~K},
\end{aligned}
$$

with kinetic parameters as given in Table 1 . Note that under the conditions at which the threeway catalyst operates many more reactions occur, in particular the ones involving adsorbed $\mathrm{CO}$ and $\mathrm{H}$, which remove adsorbed oxygen atoms at low temperatures.

In analogy with the results of theoretical calculations on the dissociation path of $\mathrm{CO}$ on rhodium by De Koster and van Santen [8], we visualize the rupture of the $\mathrm{N}-\mathrm{O}$ bond as sketched in Fig. 8. Starting from a three-fold position, the adsorbed NO molecule bends across a rhodium atom to the next three-fold site. By stretching over the central rhodium atom, the antibonding NO orbitals have a strong interaction with the $\mathrm{Rh} d$ orbitals, and the $\mathrm{N}-\mathrm{O}$ bond is efficiently weakened. The picture implies that NO requires an ensemble of at least five atoms on the (111) surface of an fcc transition metal in order to dissociate. This is in fair agreement with kinetic modelling, which indicates that three to four NO adsorption sites must be invoked to obtain realistic kinetic parameters [30].

\section{Concluding remarks}

The mechanism of a catalytic reaction is inevitably a sequence of several elementary reaction steps. The scheme of Fig. 1 represents only a highly simplified version of such a mechanism. Kinetic investigations of catalytic processes are by necessity always based on an input-output analysis of reactants entering and products leaving the reactor. What happens inside, and more specifically, on the surface of the catalyst, is only very incidentally accessible for direct kinetic investigations. Therefore, the surface science approach for studying the kinetics of elementary steps that occur in catalytic reactions is vitally important, because parameters such as those listed in Table 1 form the highly desirable input for the modeling of more complex reaction mechanisms.

A second reason why the kinetic parameters of elementary reaction steps are important is that, mainly through spectroscopy and computational chemistry, they provide a link between the intramolecular properties of (adsorbed) reactants and their reactivity. Statistical thermodynamics furnishes the theoretical framework for describing how equilibrium constants and reaction rate constants depend on the partition functions of vibration and rotation $[29,36,37]$. Thus, performing spectroscopy on adsorbed reactants and intermediates gives the input for computing equilibrium constants, while calculations on transition states of reaction pathways starting from structurally, electronically and vibrationally well characterized ground states enable the prediction of kinetic parameters (see, e.g., [38] for an example on the dissociation of NO on copper).

Note, however, that the kinetic descriptions given in this paper represent a simplification with respect to ignoring the possibility of lateral interactions. Ordering of adsorbates, even to the extent that reactants organize themselves in islands of substantial dimensions, has a profound influence on the kinetics. Exploration of these effects through Monte-Carlo simulations is a field of growing importance. The reader is referred to reviews by Lombardo and Bell [39] and by Kang and Weinberg [40, 41] for introductions to this subject.

To summarize, the purpose of this paper was to review several aspects of the dissociation of molecules on surfaces. The example of NO decomposition on rhodium (111) exemplifies that a dissociating molecule needs vacant sites and that dissociation on a highly covered surface is 
retarded to temperatures where desorption becomes feasible, such that sites are liberated. The results also illustrate that TPD and SSIMS form a successful combination for studying the kinetics of surface reactions in real time. Studies on the elementary surface reactions of small hydrocarbons, $\mathrm{NO}$ and $\mathrm{H}_{2}$, in the context of automotive exhaust catalysis, are presently in progress.

Acknowledgements. The author gratefully acknowledges Ton Janssens, Herman Borg, Joost Reijerse and Rutger van Santen at Eindhoven, as well as Herman Castro and Klaus Wandelt at Bonn, who were all involved in the investigations described here. Most of the work was supported by Pionier Grant PGS 70-154 from the Netherlands Organization for Scientific Research (NWO).

\section{References}

1. K.C. Taylor: Catal. Rev. Sci. Eng. 35, 457 (1993)

2. T.W. Root, L.D. Schmidt, G.B. Fisher: Surf. Sci. 150, 173 (1985)

3. S.B. Schwartz, G.B. Fisher, L.D. Schmidt: J. Phys. Chem. 92, 389 (1988)

4. D.N. Belton, S. J. Schmieg: J. Catal. 144, 9 (1993)

5. R. Hoffmann: Solids and Surfaces (VHC, Weinheim 1988)

6. J.W. Niemantsverdriet: Spectroscopy in Catalysis: An Introduction (VCH, Weinheim 1993)

7. R.A. van Santen: Theoretical Heterogeneous Catalysis (World Scientific, Singapore 1991)

8. A. de Koster, R.A. van Santen: Surf. Sci. 233, 366 (1990)

9. J.K. Nørskov, A. Houmøller, P.K. Johansson, B.I. Lundquist: Phys. Rev. Lett. 46, 257 (1981)

10. P.S. Bagus, K. Hermann, C.W. Bauschlicher, Jr: J. Chem. Phys. 81, 1966 (1984)

11. J. Harris, S. Andersson: Phys. Rev. Lett. 55, 1583 (1985)

12. I. Panas, P.E.M. Siegbahn: J. Chem. Phys. 92, 4625 (1990)

13. S. Holloway, G.R. Darling: Com. At. Mol. Phys. 27, 341 (1992)

14. R.A. van Santen, M. Neurock: Catal. Rev. Chem. Eng. (1995) (in press)

15. H.P. Bonzel: Surf. Sci. Rep. 8, 43 (1987)

16. Physics and Chemistry of Alkali Metal Adsorption. H.P. Bonzel, A.M. Bradshaw, G. Ert1 (eds.) (Elsevier, Amsterdam 1984)
17. M.P. Kiskinova: in Studies in Surface Science and Catalysis, Vol. 70 (Elsevier, Amsterdam 1992)

18. N.D. Lang, S. Holloway, J.K. Nørskov: Surf. Sci. 150, 24 (1985)

19. T.V.W. Janssens, G.R. Castro, K. Wandelt, J.W. Niemantsverdriet: Phys. Rev. B 49, 14599 (1994)

20. K. Wandelt: In Chemistry and Physics of Solid Surfaces VIII, ed. by R. Vanselow, R. Howe, Springer Ser. Surf. Sci., Vol. 22. (Springer, Berlin, Heidelberg 1991) p. 289

21. T.V.W. Janssens, J.W. Niemantsverdriet, R.A. van Santen: J. Chem. Phys. 101, 2995 (1994)

22. G. Brodén, G. Gafner, H.P. Bonzel: Surf. Sci. 84, 295 (1979)

23. V. Dose, I. Rogozik, A.M. Bradshaw, K.C. Prince: Surf. Sci. 179, $90(1987)$

24. K.J. Uram, L. Ng, J.T. Yates: Surf. Sci. 177, 253 (1986)

25. R.A. dePaola, J. Hrbek, F.M. Hoffmann: J. Chem. Phys. 82, 2484 (1985)

26. J.E. Crowell, G.A. Somorjai: Appl. Surf. Sci. 19, 73 (1984)

27. G. Pirug, H.P. Bonzel: Surf. Sci. 199, 371 (1988)

28. L.J. Whitman, W. Ho: J. Chem. Phys. 83, 4808 (1985)

29. R.A. van Santen, J.W. Niemantsverdriet: Chemical Kinetics and Catalysis (Plenum, New York 1995)

30. H.J. Borg, J.F.C.J.M. Reijerse, R.A. van Santen, J.W. Niemantsverdriet: J. Chem. Phys. 101, 10052 (1994)

31. L.A. DeLouise, N. Winograd: Surf. Sci. 138, 417 (1984); ibid. 159, 199 (1985)

32. V. Schmatloch, I. Jirka, N. Kruse: Surf. Sci. 297, L100 (1993)

33. C.M. Greenlief, J.M. White: in Physical Methods of Chemistry IX. ed. by B.W. Rossiter, R.C. Baetzold (Wiley, New York 1992)

34. H.J. Borg, J.W. Niemantsverdriet: in Catalysis: A Specialist Periodical Report, ed. by J.J. Spivey, A.K. Agarwal (Royal Society of Chemistry, London 1994) Vol. 11, p. 1

35. A. Brown, J.C. Vickerman: Surf. Sci. 117, 154; (1982); ibid. 124, 267 (1983); ibid. 151, 319 (1985)

36. V.P. Zhdanov: Elementary Physico-Chemical Processes on Surfaces (Plenum, New York 1991)

37. W.H. Weinberg: in Dynamics of Gas-Surface Interactions, ed. by C.T. Rettner, M.N.R. Ashfold (The Royal Society of Chemistry, Cambridge 1991)

38. M.A. van Daelen, Y.S. Li, J.M. Newsam, R.A. van Santen: Chem. Phys. Lett. 226, 100 (1994)

39. SJ. Lombardo, A.T. Bell: Surf. Sci. Rep. 13, 1 (1991)

40. H.C. Kang, W.H. Weinberg: Acc. Chem. Res. 25, 253 (1992)

41. H.C. Kang, W.H. Weinberg: Surf. Sci. 299/300, 755 (1994) 